\section{An Intersectional Perspective on Stigma as a Barrier to Ef- fective HIV Self-management and Treatment for HIV-infect- ed African American Women}

\author{
Kimberly Adams Tufts* \\ Kimberly Adams Tufts, College of Health Sciences, Old Dominion \\ University
}

\begin{abstract}
Among those who are HIV-infected and striving to live well with HIV, African American women have poorer health outcomes and represent a higher portion of those women who die from HIV-related causes. These health inequalities have been associated with the presence of social determinants of health such as stigma. This analytical review asserts that stigmas precipitated by gender, race, and class in the context of HIV-related stigma constitute substantial barriers to active engagement in HIV self-management, care, and treatment for HIV-infected African American women. The utility of the intersectionality framework for analyzing how these various stigmas interact to create unique determents to effective treatment and active self-management of HIV among African American women and for serving as a foundation for intervention development is presented.
\end{abstract}

Keywords: African American women; Engagement in care; HIV; Intersectionality; Self-management; Stigma

\section{Introduction}

African Americans living with HIV are least likely to be enrolled in continuous HIV care and treatment or to achieve viral suppression [1]. African American women, in particular, represent a higher proportion of persons living with HIV at all stages of the virus' progression from initial infection to death [2]. More specifically, $64 \%$ of women living with HIV are African American, and the majority of HIV-related deaths among women occur among African American

*Corresponding author: Kimberly Adams Tufts, College of Health Sciences, Old Dominion University, 3134A Health Sciences Building, Norfolk, VA USA Tel: +1 7576835011; +1 7576835253; E-mail: KTufts@odu.edu

Citation: Tufts KA (2015) An Intersectional Perspective on Stigma as a Barrier to Effective HIV Self-management and Treatment for HIV-infected African American Women. J AIDS Clin Res Sex Transm Dis 2: 005.

Received: July 17, 2015; Accepted: September 12, 2015; Published: October 02, 2015 women [2,3]. African American women also experience poorer health outcomes compared to others living with HIV [1].

Caiola and associates [4] suggest that intersectionality is a fitting framework for analyzing the complex health inequalities that occur among various HIV-infected sub-populations. Empirical evidence suggests that barriers to HIV self-management and treatment among African American women hinge on something more than simple adherence to Antiretroviral Therapy (ART). Consider, for example, that the mortality of African American women living with HIV is greater than that of White men, after adjusting for the duration of ART $[3,5]$. The foundation for these health inequalities have, at times, been framed as something inherent about African American women themselves-due to misbehavior and/or lack of judgment [6]. However, others have attributed these inequalities to socioenvironmental factors including interpersonal stresses and differences in health care quality [7-9].

This article presents an empirically-based argument about stigma as a formidable obstacle to self-management, care and treatment. Intersectionality is presented as a framework for analyzing and understanding the multilayered stigmas $[10,11]$ that face African American women who live with HIV. The multiplicative negative effects of these stigmas, especially in terms of impacts on health outcomes: diminished perceived quality of life, poorer rates of retention in HIV care and treatment, and suboptimal self-management of HIV are highlighted. In conclusion, it is asserted that clinical and research interventions designed to increase these women's engagement in HIV care and treatment must explicitly address the complexities of stigma.

\section{Stigma}

The term stigma refers to circumstances under which society views an individual as somehow tainted due to an attribute possessed by that particular individual [12]. Hence, stigma is a social process wherein those who are subjected to stigmatization have decreased power in the society. Stigma presents in several forms including enacted, perceived, internalized, and anticipated. Enacted stigma refers to sanctions applied individually or collectively, such as discrimination or bias. Perceived stigma results from negative social attitudes that affected persons experienced. Self or internalized stigma refers to accepting negative attitudes and beliefs, and applying these attitudes and beliefs to one's self. Internalized feelings of shame or guilt characterize this form of stigma. Anticipated stigma is an expectation of future stigmatizing experiences such as prejudice, discrimination, and stereotyping.

Socially endorsed stigmas often predetermine which social or cultural groups will be stigmatized. Consequently in many societies; women, those from ethnic minority backgrounds, and those with less economic power may experience multiple stigmas which are synergistic in nature, i.e., interacting together with each stigma contributing to the magnification of potential barriers to optimal health outcomes [13]. The theory of intersectionality assumes that socially constructed identities such as gender, race and class, interact in the context of social and power relations to create a unique health 
experience. Therefore, intersectionality is a useful framework for analyzing the syndemic impact of these stigmas on the HIV-infected African American woman's health care experience.

\section{Intersectionality}

The examination of power differentials; relationships between dominants and subordinates is at the core of the intersectional framework. Intersectionality was not developed to predict actions or cognitive processes; rather, it is a framework for analysis [14]. Intersectionality puts forth that HIV is often not the sole factor that precipitates the stigma experienced by these women; it posits that multiple factors precipitate stigmatizing experiences. An intersectional perspective acknowledges that these women's social identities experienced at the individual level (e.g., being female, an ethnic minority, and/or of low SES) interlock with oppressive forces at the macro-level of society (i.e., sexism, racismand classism) to create social injustices (e.g., health care inequalities). Intersectionality concedes that race and class are gendered thus producing compounded inequalities for marginalized groups, such as African American women. African American women were, in fact, the original focus of intersectionality theory [15].

The intersectional perspective recognizes that the socially constructed identities of these women both contribute to the woman's formative experiences and influence the sum total of these experiences. This framework acknowledges the African American woman's gender, race, class and disease conditions are not mutually exclusive. Instead, these attributes may be a collective catalyst for stigma-related experiences that are not generated by positive HIV serostatus alone; augmenting each other and contributing to stigmatizing health care encounters that further marginalize African American women living with HIV $[6,16]$.

Historical notions about the African American woman's place in US society have fueled the social construction of stereotypes. Frequently, for example, the media portrays African American women as being poor, downtrodden, hyper-sexed and as being drug users/ abusers; in a word, they are depicted as dysfunctional $[17,18]$.

Therefore, in reality, it is quite difficult to detangle the impact of one factor from another especially in the context of HIV frequently being sexually transmitted and/or due to illicit drug use. However, for purposes of clarity these factors will be presented separately to allow for a focused analysis of each factor and to illustrate have they may interact to further magnify the impact of HIV-related stigma on engagement in HIV care, treatment, and self-management.

\section{Stigma and Gender}

HIV-related stigma cannot be fully explored without taking gender into account. Gender is a social construct that does not refer to biological characteristics but rather to culturally determined role expectations for how men and women must act in society. In many societies, unequal power differentials continue to exist between men and women. Thus, gender must be considered when analyzing power structure and access to resources in the United States (US), where historically and socioculturally women have had lower social standing than men [19]. The challenges of power inequalities and group subordination within the social construction of gender have become increasingly important in the context of HIV transmission and engagement in HIV care, and treatment [20,21]. For women, HIV-related stigma is frequently layered on top of the stigma and discrimination that sexism generates. Notably, gendered experiences of daily living and their impact on access to resources, power, and influence on risk behaviors have been associated with higher risk for HIV and less than optimal HIV-related health outcomes for some groups including African American women [22].

Women, experience HIV-related stigma differently and report higher levels of HIV-related stigma [23,24]. Women living with HIV and their families are more likely to experience discrimination and a loss of social support [25-27]. In a study exploring HIV-related stigma and discrimination conducted with 536 people living with HIV (67\% female) across four sub-Saharan African countries women were significantly more likely to report interpersonal discrimination [27]. HIV-infected women are often hesitant to disclose their status for fear of being labeled promiscuous, a drug user, or simply dirty $[20,28]$. They know that disclosing their medical condition to others may jeopardize their personal relationships and economic status [21]. Lower rates of disclosure of positive serostatus among women have been associated with increased reports of mental health challenges [25]. In the case of African American women these challenges may be compounded because they may be subject to multiplicative stigmas; marginalized not only because they are women but because they are persons of color.

\section{Stigma and Race}

Socioenvironmental stresses have been associated with accelerated health deterioration among African American women when compared to US born Caucasian women. The social construction of race and race relations is prominent among the hypothesized etiologies for this phenomenon. Race has traditionally been drawn along the lines of "black and white" in the US $[29,30]$ for purposes of establishing and maintaining power differentials. Racial discrimination has been associated with higher incidences of hypertension [31] and accelerated biological aging among African Americans [32] these processes have been conceptualized as "weathering" $[9,33]$.

Many African American women experience pervasive racism throughout the life course [34]. For HIV-infected African American women gender-related stigma and the subsequent negative power differentials are often compounded by racial discrimination and/or racism. The subjective experience of racism includes subtle ideologies such as the concept of "free will," which implies that African American women's disadvantages are principally their own responsibility [35]. "Free will" can be the basis for assuming that African American women have contracted HIV due to their own risky behaviors [26]. Thus, all forms of racism, including the perpetuation of racially-based stereotypes, can contribute to the level of enacted, perceived, internalized and/or anticipated stigma that African American women living with HIV experience. Racialized stereotypes about African American women abound in pop culture: ranging from the bitchy person as depicted on "reality" TV shows to the titles of popular fiction that target African American readers [18,36]. Racialized framing can also prompt healthcare providers to assume that risks for medical conditions, such as hypertension-associated renal disease or HIV, are due to African Americans' biological characteristics, rather than due to socioeconomic and/or structural factors $[8,31,37,38]$.

Such negative racial stereotypes and their deleterious effects on African American women's self-esteem and self-image have been associated with enhanced risks for engaging in risky sexual 
behaviors, remaining in abusive relationships, and contracting HIV [39]. The intersectional perspective asserts that when an African American woman contracts HIV, negative historical stereotypes are augmented by additional stereotypes about promiscuity, drug use, lack of capacity for engaging in positive health behaviors (e.g., poor potential for adherence), and by the stigma associated with these stereotypes. Socially-constructed, negative images about race and HIV may color provider-patient interactions, ultimately limiting the potential for an effective therapeutic relationship.

\section{Stigma and Class}

Persons living with HIV, who also have lower incomes, have reported higher levels of stigma [40]. This is particularly disconcerting, because HIV has been termed a pandemic of the poor [41]. Similar to other health inequalities [42], risk and prevalence of HIV have also been associated with lower educational attainment and under- or unemployment-and are, thus, associated with lower Socioeconomic Status (SES), where SES is generally an aggregate measure of education, income, and occupational status. Nonetheless, SES is often conceptualized as class or social standing, when viewed through a social class lens, which emphasizes privilege, power, and control.

Notably, African American women are most often cared for by White health care providers of upper-middle class or upper-class standing [43]. In the context of these status inequalities, HIV-infected African American women are frequently assumed to be of a lower socioeconomic standing, until they prove otherwise [19,44,45]. If a provider possesses implicit biases about persons of lower socioeconomic status, African American women can be presumed to be noncompliant, "lost causes". These presumptions may impact these women's care and treatment [46-48]. In fact, compared to men, women are less likely to receive ART [49]. Hence, when one considers the contexts of race and class in addition to gender, African American women may be even less likely to receive ART in a timely fashion and may be more likely to experience the sequelae of inadequate viral suppression such as chronic inflammation [50]. Biased perspectives of socioeconomic status can combine with HIV-related stigma to create a less therapeutic provider to patient relationship. This was apparently the case for a group of HIV-infected African American women who participated in a qualitative study on stigma and HIV. At times these women reportedly felt socially shunned and disregarded when accessing healthcare services [26].

Intersectionality concedes that at the point of service, the African American woman often faces classism in addition to sexism and racism. The African American woman of lower socioeconomic means is frequently viewed as possessing little privilege or power. She must be directed as to how to care for herself and is expected to comply with instructions, rather than be free to participate in mutual goal-setting about her own health and self-management of HIV. Additionally, if public funds support her HIV care and treatment (i.e., Medicaid, Ryan White), she is often viewed as one of the collective "undeserving poor" [51]. At times her circumstances including that of being HIV-infected may be considered to be the result of her own individual failures, rather than of societal or systemic failures.

\section{Stigma and HIV}

Unfortunately, due to the nature of most HIV transmissions, HIV is often believed to be contracted as a penalty for misbehavior or lack of judgment [52]. Thus, not unlike other stigmas, HIV-related stigma is also a sociocultural phenomenon. HIV-related stigma is a prejudice that discounts, devalues, and discriminates against persons believed to have HIV along with other individuals and/or communities with which these persons are presumed to be affiliated [53]. A 2015 synthesis of 55 qualitative studies revealed that people living with HIV commonly report that they have encountered stigma in healthcare settings [54]. Gagnon's recent interviews of $21 \mathrm{HIV-infected} \mathrm{persons} \mathrm{exposed}$ that stigmatizing interactions, though episodic in nature, continue to persist in health care settings in the form of individual interactions and institutional policy [55]. Notably, HIV-related stigma has been associated with less than optimal HIV-related health outcomes including decreased likelihood of initiating HIV care [56], ART non-adherence, CD4 counts less than 200 cells/mm and higher prevalence of co-morbidities $[57,58]$.

Stigma takes several forms for persons living with HIV: enacted, perceived, internalized and/or anticipated [52,53,57]. All forms trigger anxiety or fear about other people's reactions to one's serostatus. Notably, stigmatizing experiences have been shown to be predictors of lack of engagement in HIV care and treatment as evidenced by missed health care appointments [40]. Different forms of stigma seemingly may have diverse influences on health status. Recently, Earnshaw and colleagues put forth that specific forms of HIV-related stigma were associated with different health behaviors and outcomes. For example, internalized stigma was specifically associated with ART non-adherence while enacted and anticipated stigma were linked to the presence of co-morbid conditions and lower CD4 counts [57]. Anticipated stigma has also been linked with patterns of HIV disclosure [21].

Hence, HIV-infected African American women who perceive HIV-related stigma in addition to other interlocking forms of stigma, may then experience shame, guilt, and depression, and conclude they are unworthy of self-care and good health, resulting less than optimal engagement in HIV self-management, care and treatment $[10,11,23,59,60]$. Intersectionality allows that their trepidation about the possibility of being discounted, devalued, and discriminated against due to being HIV-infected in the context their gender, race and class may multiply to present a nearly insurmountable barrier to effective HIV self-management and active engagement in treatment [27].

\section{Engagement in HIV Care, Treatment and Self-man- agement}

There is a preponderance of evidence that active self-management positively impacts outcomes for persons living with chronic diseases. Adherence to prescribed medical regimens and engaging in active self-management of HIV are essential to living well with HIV. Whatever the source, stigma affects disclosure patterns, health outcomes, and quality of life for those living with HIV [43,60-62]. Social support has been identified as a facilitator of self-management of HIV and significantly associated with positive coping for women living with HIV [16,63]. African American women who encounter and/or anticipate stigma related to HIV, may infer that engaging in HIV self-management might disclose their serostatus directly or indirectly-thus, jeopardizing their actual or potential social support networks.

This perspective is not without justification, given what is known about gender differences and HIV-related stigma. Compared to men, 
being a woman has been associated with higher levels of stigmatized attitudes toward persons living with HIV $[64,65]$ and women most often look to other women for social support. It is, therefore, hardly surprising that African American women might not present readily for HIV care or take ART; they may anticipate that such services will impact confidentiality within their communities, resulting in a loss of social support from other women. As emphasized earlier, loss of social support due to stigma also compromises health outcomes as a result of enhanced risk for non-adherence to ART [58] and less than optimal self-management [16]. Accordingly, preserving confidentiality and neutralizing potentially stigmatizing interactions are foundational to HIV care and treatment services and when designing programmatic and investigational interventions.

\section{Conclusion}

African American women constitute a specific population who carry distinct sociocultural luggage into the realm of HIV care and treatment. They have often experienced structural inequalities related to gender, race and class. Alas, in the case of the African American woman the presence of HIV infection may be spur additional stigma that further compounds the stigmas generated by these pre-existing factors. Conversely stigma related to HIV infection may be magnified in the presence of female gender, black race and lower socioeconomic status $[10,20]$.

Intersectionality helps us to recognize and begin to understand the social constructs and power relationships that precipitate stigmas and the multiplicative effects of various forms of stigma on these women's view of themselves, their material resources, propensity for engaging in HIV self-management, and their perceived access to health care services. Yet, HIV-infected African American women do not have to be victims of stigma; they can be resilient and resourceful even in the face of this virus $[26,57]$. Health care providers and researchers have a responsibility to employ stigma neutral gender-specific and culturally relevant interventions that promote resiliency in these women.

Evidence-based stigma reduction interventions are limited. Most interventions teach clinicians about stigma and its affect instead of helping them to effectively address the various underlying sources of their own stigmas and enabling them to build capacity for assisting persons living with HIV to successfully copy with stigmatization $[10,66,67]$. Interventions designed to assist HIV-infected African American women live well with HIV and to enhance their health outcomes must strategically minimize the impact of stigma, while incorporating methods for facilitating strong social support networks and adaptive coping. Specifically, these interventions must take into account the intersectional perspective; accounting for the negative racialized and class-based ideologies, images, narratives, and implicit bias $[47,48]$ that color health care interactions for African American women living with HIV. Such initiatives must recognize that, when these women perceive that stigma is at work, they will not be likely to engage fully in their own care or be skilled at self-managing their illness. Therefore, it is imperative that the design and development of culturally relevant gender-specific stigma reduction strategies be at the forefront of any public health efforts to decrease community-specific levels of HIV incidence and prevalence not relegated to the bottom of budgetary priorities.

\section{References}

1. Hall HI, Frazier EL, Rhodes P, Holtgrave DR, Furlow-Parmley C, et al. (2013) Differences in human immunodeficiency virus care and treatment among subpopulations in the United States. JAMA Intern Med 173: 1337-1344.

2. Centers for Disease Control and Prevention (2012) HIV in the United States: At a glance. Statistics Center, HIVIAIDS, Centers for Disease Control and Prevention, USA.

3. Centers for Disease Control and Prevention (2013) HIV among African American women. Centers for Disease Control and Prevention, USA.

4. Caiola C, Docherty SL, Relf M, Barroso J (2014) Using an intersectional approach to study the impact of social determinants of health for African American mothers living with HIV. ANS AdvNursSci 37: 287-298.

5. Lemly DC, Shepherd BE, Hulgan T, Rebeiro P, Stinnette S, et al. (2009) Race and sex differences in antiretroviral therapy use and mortality among HIV-infected persons in care. J Infect Dis 199: 991-998.

6. Peltzer JN, Domian EW, Teel CS (2014) Infected lives: lived experiences of young African American HIV-positive women. West J Nurs Res.

7. Chin $\mathrm{MH}$, Walters $\mathrm{AE}$, Cook SC, Huang ES (2007) Interventions to reduce racial and ethnic disparities in health care. Med Care Res Rev 64: 7-28.

8. Feagin J, Bennefield Z (2014) Systemic racism and US health care. Soc Sci Med 103: 7-14.

9. Geronimus AT, Hicken M, Keene D, Bound J (2006) "Weathering" and age patterns of allostatic load scores among blacks and whites in the United States. Am J Public Health 96: 826-833.

10. Mahajan AP, Sayles JN, Patel VA, Remien RH, Sawires SR, et al. (2008) Stigma in the HIVIAIDS epidemic: a review of the literature and recommendations for the way forward. AIDS 22: 67-79.

11. Rogers SJ, Tureski K, Cushnie A, Brown A, Bailey A, et al. (2014) Layered stigma among health-care and social service providers toward key affected populations in Jamaica and The Bahamas. AIDS Care 26: 538-546.

12. Goffman E (1963) Stigma; Notes on the management of spoiled identity. Prentice Hall, New Jersey, USA.

13. Singer M, Clair S (2003) Syndemics and public health: reconceptualizing disease in bio-social context. Med Anthropol Q 17: 423-441.

14. Kelly UA (2009) Integrating intersectionality and biomedicine in health disparities research. ANS Adv Nurs Sci 32: 42-56.

15. hooks b (1981) Ain't I a woman: Black women and feminism. South End Press, Boston, MA, USA.

16. Tufts KA, Wessell J, Kearney T (2010) Self-care behaviors of African American women living with HIV: a qualitative perspective. J Assoc Nurses AIDS Care 21: 36-52.

17. Woodard JB, Mastin T (2005) Black womanhood: "Essence" and its treatment of stereotypical images of Black women. Journal of Black Studies 36 : 264-281.

18. Givens SM, Monahan JL (2005) Priming Mammies, Jezebels, and Other Controlling Images: An Examination of the Influence of Mediated Stereotypes on Perceptions of an African American Woman. Media Psychology 7: 87-106.

19. Phelan JC, Lucas JW, Ridgeway CL, Taylor CJ (2014) Stigma, status, and population health. Soc Sci Med 103: 15-23.

20. Logie CH, James L, Tharao W, Loutfy MR (2011) HIV, gender, race, sexual orientation, and sex work: a qualitative study of intersectional stigma experienced by HIV-positive women in Ontario, Canada. PLoS Med 8: 1001124.

21. Kiula ES, Damian DJ, Msuya SE (2013) Predictors of HIV serostatus disclosure to partners among HIV-positive pregnant women in Morogoro, Tanzania. BMC Public Health 13: 433.

22. El-Bassel N, Caldeira NA, Ruglass LM, Gilbert L (2009) Addressing the unique needs of African American women in HIV prevention. Am J Public Health 99: 996-1001. 
23. Colbert AM, Kim KH, Sereika SM, Erlen JA (2010) An examination of the relationships among gender, health status, social support, and HIV-related stigma. J Assoc Nurses AIDS Care 21: 302-313

24. Sandelowski M, Lambe C, Barroso J (2004) Stigma in HIV-positive women. J Nurs Scholarsh 36: 122-128.

25. Beaulieu M, Otis J, Blais M, Godin G, Cox JJ, et al. (2012) A model of quality of life of women living with HIV. Journal of HIVIAIDS \& Social Services 11: 210-232.

26. Buseh AG, Stevens PE (2006) Constrained but not determined by stigma: resistance by African American women living with HIV. Women Health 44: 1-18

27. Neuman M, Obermeyer CM, MATCH Study Group (2013) Experiences of stigma, discrimination, care and support among people living with HIV: a four country study. AIDS Behav 17: 1796-1808

28. Carr RL, Gramling LF (2004) Stigma: a health barrier for women with HIV/ AIDS. J Assoc Nurses AIDS Care 15: 30-39.

29. Bradby H (2012) Race, ethnicity and health: the costs and benefits of conceptualising racism and ethnicity. Soc Sci Med 75: 955-958.

30. Smedley A, Smedley BD (2005) Race as biology is fiction, racism as a social problem is real: Anthropological and historical perspectives on the social construction of race. Am Psychol 60: 16-26.

31. Chae DH, Nuru-Jeter AM, Adler NE (2012) Implicit racial bias as a moderato of the association between racial discrimination and hypertension: A study of midlife African American men. Psychosom Med 74: 961-964.

32. Chae DH, Nuru-Jeter AM, Adler NE, Brody GH, Lin J, et al. (2014) Discrimination, racial bias, and telomere length in African-American men. Am J Prev Med 46: 103-111.

33. Chyu L, Upchurch DM (2011) Racial and ethnic patterns of allostatic load among adult women in the United States: findings from the national health and nutrition examination survey 1999-2004. J Womens Health (Larchmt) 20 $575-583$.

34. Nuru-Jeter A, Dominguez TP, Hammond WP, Leu J, Skaff M, et al. (2009) "It's the skin you're in": African-American women talk about their experiences of racism. An exploratory study to develop measures of racism for birth outcome studies. Matern Child Health J 13: 29-39.

35. Yetman NR (1985) Introduction: Definitions and perspectives. In: Yetman NR (ed.). Majority and minority: The dynamics of race and ethnicity in American life, (4thedn). Allyn \& Bacon, Boston, USA. Pg no: 1-20.

36. King D (2011) Bitch: A new beginning. King Productions, Collierville, TN, USA.

37. Anderson NB (1999) Solving the puzzle of socioeconomic status and health the need for integrated, multilevel, interdisciplinary research. Ann N Y AcadSci 896: 302-312.

38. Clark R, Anderson NB, Clark VR, Williams DR (1999) Racism as a stressor for African Americans. A biopsychosocial model. Am Psychol 54: 805-816.

39. Centers for Disease Control and Prevention (CDC) (2005) HIV transmission among black women--North Carolina, 2004. MMWR Morb Mortal Wkly Rep 54: 89-94.

40. Vanable PA, Carey MP, Blair DC, Littlewood RA (2006) Impact of HIV-related stigma on health behaviors and psychological adjustment among HIV-positive men and women. AIDS Behav 10: 473-482.

41. Pellowski JA, Kalichman SC, Matthews KA, Adler N (2013) A pandemic of the poor: social disadvantage and the US HIV epidemic. Am Psychol 68 : 197-209

42. Fuller-Thomson E, Nuru-Jeter A, Minkler M, Guralnik JM (2009) Black-White disparities in disability among older Americans: further untangling the role of race and socioeconomic status. J Aging Health 21: 677-698.

43. Association of American Medical Colleges (2010) Diversity in the Physician Workforce: Facts \& Figures 2010. Washington, DC, USA.
44. Berger J (1977) Status characteristics and social interaction: an expectation-states approach. Elsevier scientific Pub. Co., New York, USA.

45. Major B, Mendes WB, Dovidio JF (2013) Intergroup relations and health disparities: a social psychological perspective. Health Psychol 32: 514-524.

46. Earnshaw VA, Bogart LM, Dovidio JF, Williams DR (2013) Stigma and racial/ ethnic HIV disparities: moving toward resilience. Am Psychol 68: 225-236.

47. Haider AH, Sexton J, Sriram N, Cooper LA, Efron DT, et al. (2011) Association of unconscious race and social class bias with vignette-based clinical assessments by medical students. JAMA 306: 942-951.

48. Sabin JA, Rivara FP, Greenwald AG (2008) Physician implicit attitudes and stereotypes about race and quality of medical care. Med Care 46: 678-685.

49. Aziz M, Smith KY (2011) Challenges and successes in linking HIV-infected women to care in the United States. Clin Infect Dis 52: 231-237.

50. Stone VE (2005) Physician contributions to disparities in HIVIAIDS care: the role of provider perceptions regarding adherence. Curr HIVIAIDS Rep 2: 189 193.

51. Kovner AR, Jonas S (2002) Jonas \& Kovner's Health care delivery in the United States, (7thedn). Springer Publishing Company, New York, USA.

52. Office on Women's Health (2013) An interview with an HIV+ woman: Dawn Averitt. News, Office on Women's Health, US Department of Health and Human Services, USA

53. Herek GM, Capitanio JP, Widaman KF (2002) HIV-related stigma and knowledge in the United States: prevalence and trends, 1991-1999. Am J Public Health 92: 371-377.

54. Chambers LA, Rueda S, Baker DN, Wilson MG, Deutsch R, et al. (2015) Stigma, HIV and health: a qualitative synthesis. BMC Public Health 15: 848.

55. Gagnon M (2015) Re-thinking HIV-Related Stigma in Health Care Settings: A Qualitative Study. J Assoc Nurses AIDS Care.

56. Pollini RA, Blanco E, Crump C, Zúñiga ML (2011) A community-based study of barriers to HIV care initiation. AIDS Patient Care STDS 25: 601-609.

57. Earnshaw VA, Smith LR, Chaudoir SR, Amico KR, Copenhaver MM (2013) HIV stigma mechanisms and well-being among PLWH: a test of the HIV stigma framework. AIDS Behav 17: 1785-1795.

58. Katz IT, Ryu AE, Onuegbu AG, Psaros C, Weiser SD, et al. (2013) Impact of HIV-related stigma on treatment adherence: systematic review and meta-synthesis. J Int AIDS Soc 16: 18640

59. Konkle-Parker DJ, Erlen JA, Dubbert PM (2008) Barriers and facilitators to medication adherence in a southern minority population with HIV disease. $J$ Assoc Nurses AIDS Care 19: 98-104.

60. Clark HJ, Lindner G, Armistead L, Austin BJ (2003) Stigma, disclosure, and psychological functioning among HIV-infected and non-infected African-American women. Women Health 38: 57-71.

61. Rao D, Kekwaletswe TC, Hosek S, Martinez J, Rodriguez F (2007) Stigma and social barriers to medication adherence with urban youth living with HIV. AIDS Care 19: 28-33.

62. Vyavaharkar M, Moneyham L, Corwin S, Saunders R, Annang L, et al. (2010) Relationships between stigma, social support, and depression in HIV-infected African American women living in the rural Southeastern United States. J Assoc Nurses AIDS Care 21: 144-152.

63. Grodensky CA, Golin CE, Jones C, Mamo M, Dennis AC, et al. (2015) "I should know better": The roles of relationships, spirituality, disclosure, stigma, and shame for older women living with HIV seeking support in the South. $J$ Assoc Nurses AIDS Care 26: 12-23

64. Mugoya GC, Ernst K (2014) Gender differences in HIV-related stigma in Kenya. AIDS Care 26: 206-213.

65. Ugarte WJ, Högberg U, Valladares EC, Essén B (2013) Measuring HIV- and AIDS-related stigma and discrimination in Nicaragua: results from a community-based study. AIDS Educ Prev 25: 164-178. 
Citation: Tufts KA (2015) An Intersectional Perspective on Stigma as a Barrier to Effective HIV Self-management and Treatment for HIV-infected African American Women. J AIDS Clin Res Sex Transm Dis 2: 005

- Page 6 of 6 •

66. Griffith JL, Kohrt BA (2015) Managing Stigma Effectively: What social psychology and social neuroscience can teach us. Acad Psychiatry.
67. Sengupta S, Banks B, Jonas D, Miles MS, Smith GC (2011) HIV interventions to reduce HIVIAIDS stigma: a systematic review. AIDS Behav 15: 1075-1087. 